\title{
Self-actualization from an Eastern Perspective-A Preliminary Exploration
}

\author{
Jyothsna Kamath Burde • \\ Ashok Honnedevasthana Shama Rao
}

Received: 12 June 2010 / Accepted: 19 May 2011 / Published online: 16 June 2011

(C) National Academy of Psychology (NAOP) India 2011

\begin{abstract}
Growth of the branches of humanistic and positive psychology has brought in a paradigm shift in the understanding of human nature and behavior from the reductionistic and mechanistic perspectives. Emphasis on the study of the self necessitates greater use of a qualitative subjective methodological framework. In this respect, the current Western approach falls short in front of the Eastern philosophy, which has an array of such procedures and methodologies, which practitioners of humanistic and positive psychology are now exploring. The Indian systems of thought elaborate on the means to realizing or knowing the true nature of the self within, through the multifaceted and individualized process of Yoga. Alternative systems of Yoga are provided that could be practiced by individuals based on their subjective preferences and suitability. The major alternatives that have been identified are Bhakti, Jnana, Karma and Raja Yoga. In this context, the present study is a pilot attempt to explore self-actualization among practitioners of two paths of Yoga i.e. Bhakti Yoga and Jnana Yoga. The opinions and beliefs of the practitioners on variables related to the self and its actualization, as also their world-views are explored. Implications on personality, distinguishing characteristics and the functioning of self are proposed, to enable an individual to adopt a suitable path.
\end{abstract}

Keywords Self-actualization $\cdot$ Yoga $\cdot$ Bhakti Yoga $\cdot$ Jnana Yoga

J. Kamath Burde $(\bowtie) \cdot$ A. Honnedevasthana Shama Rao

Department of Psychology, Bangalore University,

Jnanabharathi,

Bangalore 560 056, India

e-mail: jyothsna.kamath@gmail.com

A. Honnedevasthana Shama Rao

e-mail: ashokbub@gmail.com

\section{Introduction}

A concern towards enhancing adjustment and individual strengths to develop human potential to its maximum is the hallmark of humanistic psychology. As against a focus on pathology and abnormality, this branch is primarily concerned with the concept of self, the search for identity, the importance of the universal human motive of self-actualization as the fulfillment of one's own potentialities and basic nature, cognitive and spiritual growth, psychological health and selftranscendence (Winthrop 1963). Borrowed from Goldstein (1939), the term self-actualization is defined as the process of becoming all that one is capable of, by utilizing innate potential and available resources.

As part of furthering the humanistic movement, it is being recognized that systems of thought with similar concerns have originated in the Eastern part of the world. The Eastern, and predominantly the Asian systems are derived from religious and spiritual systems (Walsh and Vaughn 1987) and are deeply embedded in their respective philosophies which are committed to advancing these very goals of the highest human development. In them, are delineated concepts of uniquely human qualities, innate infinite potential of the human being, the restricting influence of personal and social conditioning that hinder self-identity and self-fulfillment, resolution of the existential crisis and the potential to reach increasingly higher levels of development. Modern Western psychology is currently exploring the Eastern traditions to supplement existing knowledge about the means by which a healthy individual can actualize his potential. These avenues provide an alternative approach in bridging the gap in understanding human nature.

The humanistic concept of self-actualization is, in a way, comparable to that of self-realization in the eastern 
traditions. The ultimate goal of life according to most of the eastern and specifically the Indian philosophical systems is self-realization. The process of achieving the realization of the self occurs by a process of deconditioning and consequent transformation of the person to achieve higher states of awareness and achievement (Rao and Marwaha 2005).

Several alternative paths have been proposed in various texts to achieve the realization, especially in the Bhagavad Gita, which accepts the effectiveness of and synthesizes the different methods of Yoga prevalent at the time. Though the different paths of Yoga predate the organized thought systems, philosophical rationalizations for these paths are found in the major schools of Vedantik thought. These systems are built around certain specific ontological and epistemological assumptions. Consequently they offer differing conceptions about the nature of the self, goal of its actualization and the means adopted towards that end. The primacy of each of these paths to achieve self-realization thus varies according to the philosophical system.

Some of the major concerns of these systems such as one's concepts of the self, the perceived goal of existence which offers a direction for the individual's growth and development, and the means to achieve the goal, are nested in larger systems relating to one's role in the scheme of things, and herewith, more fundamental questions about the source, nature and purpose of creation. The present study is a pilot investigation that aims at comparing these viewpoints of the two paths, so that a picture of typical practitioners can be drawn which could help an aspirant of self-actualization to adopt the most appropriate path.

The primary objective of the study is to gain an understanding of the eastern perspectives to present self-actualization. A review of available theoretical literature indicates various commonalities as well as divergences in the view of self, self-actualization and world-views among active selfactualizers across different paths. The Eastern perspective refers to the psychologically relevant content in ancient Indian philosophical literature. In this study it encompasses the process of self-actualization assessed in terms of the paths of Yoga (Bhakti Yoga and Jnana Yoga) an individual adheres to.

\section{Method}

A two-group design was used consisting of two groups of Yoga practitioners-those of Bhakti Yoga and Jnana Yoga. The sample was identified using the snowball sampling technique and constituted residents of Bangalore city with an age range of 35 to 70 years, with an average age of 57.59 years. Participants were required to have been practitioners of a path for a minimum period of 5 years.

As a tool for self-actualization, Bhakti Yoga emphasizes development of an affective devotional relationship with a chosen personal god while Jnana Yoga upholds rational understanding of the truth underlying phenomena. Jnana Yoga as a tool in search of the truth is also characteristic of the scientific approach to understanding phenomena. The integral and unified conception of reality has been the most spectacular achievement of the new age scientific thinking. The scientific view of the universe and man as a manifestation of a single absolute principle finds a parallel in Advaita Vedanta which views the observable phenomena as a manifestation of an absolute underlying reality. Thus despite differences in the methodologies utilized, with science giving primacy to the observation and experimentation, and Advaita Vedanta to speculation and reasoning, yet the notion of apparent empirical reality being sublated by a single absolute principle in the course of new discoveries is the common thread between the two approaches (Mishra 2002).

\begin{tabular}{|c|c|c|c|c|c|c|c|c|c|}
\hline \multicolumn{4}{|c|}{ Bhakti Yoga } & \multicolumn{6}{|c|}{ Jnana Yoga } \\
\hline \multirow{2}{*}{\multicolumn{2}{|c|}{ Dvaita Vedanta $(n=5)$}} & \multicolumn{2}{|c|}{ Vishishtadvaita Vedanta $(n=6)$} & \multicolumn{2}{|c|}{ Advaita Vedanta $(n=6)$} & \multicolumn{4}{|c|}{ Scientists $(n=5)$} \\
\hline & & & & & & Theor & hysics $(n=2)$ & Life s & $\operatorname{ces}(n=3)$ \\
\hline Male & Female & Male & Female & Male & Female & Male & Female & Male & Female \\
\hline 3 & 2 & 4 & 2 & 4 & 2 & 1 & 1 & 2 & 1 \\
\hline
\end{tabular}

\section{Measures}

Adequate exploration of the philosophical pursuit of the quest for realizing the self is possible through an alternative qualitative, and often a phenomenological, approach. Hence a semi-structured interview was used (given in Appendix A). The interview was conducted individually with each subject to gain an insight into the subjects' conceptions and beliefs about self-actualization and related variables. 


\section{Results and Discussion}

The multiplicity and complexity of the Eastern tradition provides for alternative procedures for individuals to choose an appropriate form to suit their dispositions, personal needs and goals of the seekers. The theoretical information culled out from philosophical literature available on the paths of Yoga suggests that individuals following the two paths may differ in various ways.

The study yielded data on the practitioners' opinions about the concept of self/soul, ultimate goal or purpose of existence and the means to achieve the goal, immediate life goals, and also the nature and purpose of creation and its underlying principle. For each of the questions posed, the dominant themes of the responses of both groups were listed out. The concepts and specialized terminology mentioned were noted and the responses given were included as representing the sub-group. The table below reveals a comparison between the opinions of the practitioners of Bhakti Yoga and Jnana Yoga.

Various observations may be gleaned from a survey of the information obtained.

Certain common beliefs emerge relating to the belief in the eternality of the self, forming the basis of all activity in

\begin{tabular}{|c|c|}
\hline Concept & $\begin{array}{l}\text { Opinions of practitioners } \\
\text { Bhakti Yoga }\end{array}$ \\
\hline Self/soul & $\begin{array}{l}\text { - An eternal force of energy driving all activity } \\
\text { different for differing classes of beings } \\
\text { qualitatively and quantitatively always inferior to the supreme } \\
\text { principle believed to have created it }\end{array}$ \\
\hline $\begin{array}{l}\text { Ultimate goal of } \\
\text { existence }\end{array}$ & $\begin{array}{l}\text { To realize that each individual self is not independent but always } \\
\text { dependent on a higher spiritual creative force and must surrender to } \\
\text { its influence } \\
\text { also to rid oneself of the feeling of 'I' or the ego, and progressively } \\
\text { realize that one's self is unimportant in the larger scheme of things }\end{array}$ \\
\hline $\begin{array}{l}\text { Means to achieve } \\
\text { the goal }\end{array}$ & $\begin{array}{l}\text { Devotion and emotional bonding to a personal god through surrender to a } \\
\text { preceptor or Guru who would lead one to the desired goal }\end{array}$ \\
\hline Current status & $\begin{array}{l}\text { (They declined to accept that they had been able to make } \\
\text { considerable progress in achieving their goal and whatever little they } \\
\text { might have achieved is mainly due to the beneficial force of the } \\
\text { spiritual power they believe in to be the motivator for their actions.) } \\
\text { To live peacefully, happily }\end{array}$ \\
\hline miminediate inte gods & $\begin{array}{l}\text { Perform service to society as a duty to be executed by an instrument } \\
\text { of the divine force believed in and not claiming ownership for the } \\
\text { deed }\end{array}$ \\
\hline $\begin{array}{l}\text { Nature and Purpose } \\
\text { of creation }\end{array}$ & - The entire gamut of creation is real and not illusory \\
\hline
\end{tabular}

- Individuals must experience and overcome it to achieve the goal of reaching the supreme divine principle.

- (However, they were divided on the issue of its permanence, with some believing it to be eternal and the others believing it to be cyclical in origin and destruction)

Unifying principle underlying creation
- Preference to invest energy into an entity with form believed to be the sole orchestrator of the activity of all beings, looking after the welfare of all, inconceivably more significant than individual beings, merciful to grant prayers, powerful enough to materialize anything beyond all conceivable laws and on which all individual beings are dependent

- A formless god is suitable at a preliminary level of understanding. Comprehension of the form of the supreme principle not possible for all

\section{Jnana Yoga}

- A formless eternal energy or life force

- forms the basis of all activity of beings

- Though appearing different in different beings, it is essentially one and the same energy that exists everywhere

- To be able to maintain a steady detached objective outlook at all times and under all circumstances

- Continuously expand one's knowledge and eventually merge with the single entity that manifests itself variously

- Intensive study, comprehension and analysis of various natural phenomena and/or philosophical ideas

- (They did acknowledge that they had put in their efforts and also progressed towards their goal)

- A peaceful life

- Share and diversify the knowledge gained for the benefit of others

- Creation is real only in a relative immediate sense, with everything seeming illusory or inconsequential when seen from a larger perspective.

- Its purpose is not as important as the individual's efforts to realize that it is ultimately illusory and overcome the 'mirage' of differentiation to understand that the ultimate reality is one (AV)

- Basis of activity rooted in belief in the existence and reality of the physical world, and uncovering the underlying truth of the phenomena in the natural and physical world (Sc)

- A dimensionless abstract entity, an energy that forms the prime orderly cause of every phenomenon at a macro level

It is no different from and is within every being created.

AV - Advaita Vedanta practitioner

Sc - Scientist 
the being. This belief contributes to a sense of purpose and continued meaning to all of one's activities.

Additionally, contributing to society and others' development, and also leading a peaceful life is seen as an important life goal to realize. Self-actualization as a prime motivator of human effort has often been criticized as leading to excessive self-care and self-centeredness. Such fears could be allayed when considering the primacy given to concern for others as part of one's own development.

With regard to the comparison between groups, there is very little intra-group variation in the responses of both the sub-groups of Bhakti Yoga and Jnana Yoga. The practitioners, being drawn from similar institutions, subscribe to a particular philosophy and are homogenous with regard to fundamental beliefs, opinions and world-views. The Dvaita and Vishishtadvaita Vedanta practitioners share many theoretical assumptions about the nature of the self and the goal of its actualization. Similarly, despite differences in the approaches to reality between the Advaita Vedanta practitioners and scientists, the basic assumptions relating to the unitary nature of reality are common between the two systems. Thus typical responses are found.

In the same vein, sharp inter-group differences exist as the basic assumptions and ideas of the schools of Dvaita and Vishishtadvaita on the one hand, and Advaita system and modern science on the other, differ diametrically.

\section{Implications}

The wide differences in the various beliefs and viewpoints throw open opportunities for further inquiry. These differences may manifest in different ways.

1. The basic idea of self/soul is seen to differ among the practitioners of Bhakti Yoga and Jnana Yoga, which may have important consequences on self-related variables. The former may deem it paramount to efface his own self in front of a more powerful divine Self, in contrast to the latter who may exert efforts towards seeing their own self expanded all around. Assigning greater importance to a higher spiritual power, considering oneself as a mere tool in its hands, considering the self as inferior to and dependent on a higher power giving increasingly less importance to the self could be associated with a lowered level self-esteem in the modern psychological context of the word.

2. With regard to the process of self-actualization, the Jnana Yoga practitioner may consider devotional and emotional pursuits as even unnecessary and distracting, and direct his/her efforts towards actualizing the capabilities of the self through such intellectual inquiry, while the Bhakti Yoga practitioner may find it less fulfilling to engage in solemn reflection on the impersonal, but much more rewarding to develop an emotional relationship with a personal god, and thereby realize the self. Towards this end, the Bhakti Yoga practitioner may find it more worthwhile developing the emotional side of the personality through a wellwishing attitude and compassion toward other living entities, etc. alongside the pursuit of self-actualization, while the Jnana Yoga practitioner may engage in developing the logical thinking side of his personality to sharpen his ability to pursue this goal.

3. A Bhakti Yoga practitioner, owing to a preference for emotional bonding with a belief in the orchestrating power of a higher being, may not be driven to accomplish as much if he believes that ultimately all depends on a different superior power. This may be in contrast to those practicing Jnana Yoga, who may put forth efforts and accomplish tasks if he believes himself in reality to be an infinite reservoir of spiritual energy lying dormant. This has important implications for selfefficacy and locus of control. A higher internal locus of control may lead to difficulty in submitting to another's will, but a lower extent of this attribute may help to deal with difficult life events better since he believes his will is subject to a higher and protecting intelligence.

4. Owing to a preference for the affective side of the mind, the former may possess greater emotional intelligence and prefer using emotion-focused coping strategies in the face of crisis, whereas the latter may prefer to approach and tackle problems in a rational analytical fashion, opting for problem-focused strategies instead.

5. Preference for certain specific types of activity may be related to the proficiency with which an individual performs tasks that are either affectively or cognitively loaded. Such preferences may also manifest in the leisure activities that a person engages in.

6. The Jnana Yoga practitioners may work hard at finding the common thread underlying all phenomena in the face of seeming diversity, whereas the Bhakti Yoga practitioner, who believes in the existence of diversity among individual souls in comparison to the Supreme Self may be much more comfortable accepting the existence of diversity among people. Major differences in world-view could also stem from the beliefs these individuals hold about existence and its purpose.

7. Views of an individual on these dimensions are often most important in determining efforts towards the actualization of the perceived potentials of the self. Consequently individuals influenced, through formal or informal education, by various schools of thought 
may tend to show differences in their perceptions, beliefs, motivation and attitudes that might guide their orientation towards life and their own development. These paths also could be differentiated on the basis of personal/subjective prerequisites that are found necessary for its practice towards achieving the ultimate goal of self actualization. Unfortunately practitioners of the different paths often fail to concur on certain crucial issues and believe in championing their respective methodologies as solely instrumental for attaining the goal. In the process, the subjective prerequisites which make individuals unique are ignored, and enforcing the following of a path may give rise to incompatibility between one's self and the path of practice one has chosen.

\section{Conclusions}

The results of the present study provide some insight into alternative views of practitioners of self-actualization. The two paths of Yoga examined here are merely alternative means to an end (Rama et al. 1976). There may well be no difference in the subjective experience of the reality by individuals following either path, but conceptions of diversity may remain until then. Individuals with different endowments and shortcomings are believed to be free to choose the path they are best suited for. Without implying any causality, it may be said that preference for a specific path of Yoga is deeply connected to individual differences in attributes - a prime consideration in laying out varied paths to self-realization. Attention to the prerequisites for and the implications of practice of a path of Yoga can aid the individual to choose the path appropriate to him, rather than merely following a path due to factors like affiliation to a religion, or system of philosophy, in which efforts may not be yielding fruit. Prior to reaching this goal, the individual would do well to examine the means so as to enable himself to function better and actualize the ideal state more effectively, in accordance with his preference. By gaining insight into the appropriate path of Yoga, individuals motivated to develop their full potential of self, could choose to follow a path in order to optimize their innate potential and achieve the goal of selfactualization.

The present exploration is part of a larger project aimed at a deeper investigation into these dimensions comparing the viewpoints of Western and Eastern psychology, which is hoped will clarify many nebulous areas and enable normal healthy individuals to utilize the best of both approaches to achieve higher levels of functioning.

Note: The usage of the masculine gender in this article follows common parlance and is not intended to be gender-specific.

\section{Appendix A-Semi-structured Interview}

1. What is your conception of the self?

2. What do you hold as the ultimate goal of existence?

3. How do you go about achieving this goal?

4. How far do you believe you have progressed in this regard?

5. What are your immediate goals in life?

6. According to you, what is the nature of creation and its purpose?

7. What do you believe is the unifying principle underlying creation?

\section{References}

Goldstein, K. (1939). The organism. New York: American Book.

Mishra, H. (2002). Reality-shift: A dialogue between modern science and advaita philosophy. Paper Presented at the All India Oriental Conference, 41 Session, Puri, Orissa.

Rao, K. R., \& Marwaha, S. B. (2005). Towards a spiritual psychologyessays in indian psychology. Samvad India Foundation.

Rama, S., Weinstock, A., \& Ballentine, R. (1976). Yoga and psychotherapy: The evolution of consciousness. Illinois: Himalayan International Institute.

Walsh, R., \& Vaughn, F. E. (1987). Transpersonal psychology (II). In R. J. Corsini (Ed.), Concise encyclopedia of psychology. New York: Wiley.

Winthrop, H. (1963). Indian thought and humanistic psychology: contrasts and parallels between East and West. Philosophy East and West, 13(2), 137-154. 